Tradução / Translation

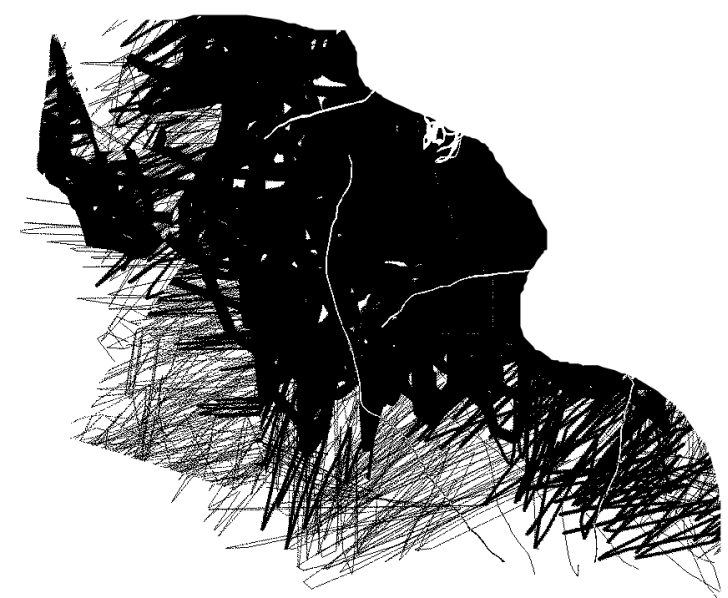




\section{Alfabetización digital. ¿De qué estamos hablando?}

Emilia Ferreiro

Las PCs acaban de cumplir 20 años (hablo de las PC, no de las computadoras).

Hace 20 años se inició la incorporación masiva de la informática al espacio laboral y, enseguida, al espacio familiar.

La idea de personal computer parecía insólita al inicio. Veinte años después hablamos con toda naturalidad de la computadora de $m i$ oficina, la de $m i$ casa, $m i$ portátil. 0 sea, encontramos natural que una persona tenga a su disposición tres computadoras diferentes, para usos parcialmente coincidentes.

Hace diez años se podía heredar una computadora. Hoy día los jóvenes de la familia reclaman procesadores poderosos, alta velocidad de navegación. Las computadoras de los adultos ya no son heredables. El reciclaje de las computadoras - por obvias razones de economía de mercado - está poco desarrollado y, en mi conocimiento, limitado a algunas ONGs de apoyo al mal llamado "tercer mundo", y a algunos proyectos informáticos de algunos pocos países.

Sirva esto de mínima introducción para decir que ya tenemos, a nivel de la educación básica, "niños informatizados”, como antes tuvimos "niños televisivos". Entiendo por esto: niños que nacieron y crecieron sabiendo que esa tecnología estaba instalada en la sociedad. Para algunos, esa tecnología estaba instalada y visible en sus casas (aunque no necesariamente "a su disposición"). Para otros (la inmensa mayoría) se trataba de una de las tantas tecnologías "objeto de deseo", pero fuera del alcance. En los dos casos, y esto es lo que me importa, nacieron con la tecnología instalada en la so-

* Trabalho apresentado em Salamanca, Espanha, publicado em: Actas de las $12^{a}$ Jornadas de Bibliotecas Infantiles y Escolares. Fundación Germán Sánchez Ruipérez, Salamanca, pp. 13-32; e em: Alfabetización de niños y adultos: textos escogidos. Centro de Cooperación Regional para la Educación de adultos en América Latina y el Caribe (CREFAL), Pátzcuaro, Michoacán, México, 2007.p. 259-278. ciedad. No es lo mismo ver llegar una tecnología que nacer con ella ya instalada. Los aquí presentes, en su mayoría al menos y a pesar de obvias diferencias de edad, pertenecemos a la generación que "vio llegar esa tecnología”. Nos pertenece la sorpresa, el asombro, el no saber si "eso" iba a ser objeto de curiosidad o de necesidad; luego vino el aprendizaje obligado y ahora el constatar que hemos establecido una nueva relación de dependencia tecnológica, hasta entonces desconocida.

Nada de eso para los niños informatizados de la nueva generación. Para ellos es tan normal enviar un mensaje a Australia apretando una tecla como para nosotros lograr una comunicación telefónica componiendo una serie de números. El verbo "discar" fue desapareciendo de nuestro léxico a medida que los discos de los aparatos telefónicos fueron sustituidos por teclas de pulsación. Los nuevos niños informatizados nunca "discaron” y muy rápidamente "chatearon".

Cuando se enseña historia casi nunca se piensa en lo difícil que resulta, para estos niños y jóvenes, imaginar mundos donde algunas de las tecnologías más distribuidas no estaban presentes. En la historia oficial de México hay algunas mujeres que son figuras emblemáticas: la Malinche (Malitzin) durante la conquista; la Corregidora, durante la Independencia. En una tarea escolar, un alumno resume: "La Corregidora llamó por teléfono a los Insurgentes”. El texto escolar dice "se comunicó", y hay que ser capaces de pensar que en 1810 no había teléfonos. (Dentro de pocos años dirán: "mandó un correo electrónico" - o un "emilio", como dicen acá en España).

Porque el verbo "comunicar", para esta nueva generación, quiere decir llamar por teléfono (de preferencia, celular) o chatear. ("iComunicate!" dicen insistentemente las 
propagandas de teléfonos celulares). El verbo “comunicar" ya no remite, de manera espontánea, a la escritura sobre papel. Tomemos nota de ello.

Cuando se habla de los nuevos niños informatizados se suele pensar en jóvenes. Permitanme presentar dos anécdotas de cómo se comportan los de 5 años. Primera anécdota. Ciudad de México, lugar público con propagandas iluminadas y protegidas por plástico flexible. Paco aprieta diferentes puntos sobre una imagen y concluye: "No funciona". No hace falta más para saber que Paco, con sus escasos 5 años, ya tiene experiencia sobre pantallas sensibles. Las otras también son potencialmente sensibles, sólo que "no funcionan".

Segunda anécdota. Buenos Aires, misa dominical. A la salida Andrés, 5 años, le dice a su madre: "Ya entendí qué quiere decir Amén". Madre, intrigada: "A ver, ¿qué quiere decir?". Andrés: "Quiere decir Enter".

Las dos anécdotas me parecen reveladoras para ilustrar lo que entiendo por "niños informatizados": niños cuyos esquemas interpretativos para entender el mundo social y para generar expectativas sobre el comportamiento de los objetos culturales están construidos a partir de "saberes informáticos", por incipientes que estos saberes sean.

De esos niños y jóvenes quiero ocuparme. De los de América Latina en primer lugar, porque de allí vengo. Algunos de estos niños $\mathrm{y}$ jóvenes tienen un conocimiento de primera mano porque hay PC en sus casas, mientras que otros tienen un conocimiento social difuso con poco, escaso o nulo contacto directo. Sin embargo, no despreciemos ciertos indicadores: hay Cafés Internet al lado de la panadería en barrios marginados tanto como en zonas turísticas; el uso de celulares alcanza a profesiones de baja calificación (por ej., un ingeniero o arquitecto lo entrega a sus obreros para controlar la obra a distancia; los camioneros deben llevarlo en ruta también para control a distancia); las series de TV y los films muestran con frecuencia crecien- te a personajes usando PCs; el gesto ya habitual de un empleado bancario o una recepcionista de hotel o de línea aérea, o incluso de una cajera de supermercado, no consiste en mirar al cliente sino a la pantalla de la computadora. (¿La computadora? ¿El computador? ¿Estamos seguros del género atribuido al aparato en cuestión?)

¿Estamos frente a una revolución en las prácticas de escritura y lectura? No soy demasiado original al decir que SI. Sin embargo, de ello no se deriva que necesitemos recurrir a la noción de "alfabetización digital".

Vayamos por partes.

Que hay una revolución en las prácticas de escritura es innegable. Dicha revolución fue preparada por la escritura a través de un teclado, invención que está disponible desde 1874 , cuando la compañia Remington (fabricante de armas) pone en el mercado las primeras máquinas de escribir.

El punto es importante porque muestra que, en ocasiones, hay una brecha temporal importante entre la disponibilidad de la tecnología y el impacto social de dicha tecnología.

¿Cuánto tiempo tardaron en imponerse algunas de las recientes tecnologías de la comunicación?

En su Reporte 1999, UNDP nos informa lo siguiente:

La radio tardó 38 años en llegar a tener 50 millones de usuarios.

La televisión tardó 13 años en llegar al mismo número de usuarios.

Internet alcanzó esa cifra en apenas 4 años.

(La computadora, sobre la cual se asienta Internet, tardó 16 años en alcanzar los 50 millones de usuarios).

Claro que las TIC (abreviatura usual para Tecnologías de la Información y la Comunicación) son mucho más que un teclado. Pero incorporan el teclado, y eso no siempre se su- 
braya. Me parece importante porque la escritura a través de un teclado ha pasado en pocos años de ser un oficio a ser parte de los "saberes del escritor" que nadie asume como instancia transmisora.

Antes, el teclado para escribir definía una instancia de aprendizaje específica llamada "dactilografía". Hoy día no hay ningún instituto privado - ni siquiera los de calidad dudosa - que promocionen la dactilografía. La escuela no se hace cargo - porque nunca se hizo cargo del teclado como instrumento de escritura. Es como si asumiéramos, implícitamente, que "da lo mismo" enfrentar el teclado de la computadora con las dos manos y con diez dedos que con algunos pocos dedos, siempre en combinación con el mouse.

Sin embargo, no da lo mismo. El ir y venir de la mirada entre la pantalla y el teclado multiplica los errores y contribuye a preferir el mouse al teclado lo cual, a su vez, contribuye a menospreciar las enormes ventajas de este teclado asociado a un procesador de palabras.(Hablando de dedos.... Las nuevas tecnologías han revalorizado uno de nuestros dedos: el pulgar. Por supuesto, este dedo es la pieza clave de la capacidad de prehensión de nuestra mano, pero la belleza de la mano se canta a través de los dedos largos, no a través de este dedo corto y regordete privilegiado - eso sí - para las huellas dactilares. Las nuevas generaciones están poniendo a prueba la movilidad de este dedo en los minúsculos aparatos digitales portátiles y en los comandos a distancia. Los jóvenes tienen una envidiable movilidad en los pulgares.)

Por supuesto, la revolución informática es mucho más que la escritura a través de un teclado. Lo importante es todo lo que cambia al mismo tiempo: los modos de producción de los textos, los modos de circulación de los textos, y la materialidad de los objetos portadores de las marcas escritas.

Los modos de producción actuales suponen una concentración de funciones en una misma persona, funciones que antes se repartían entre una variedad de oficios. Hubo una época, en la antigüedad clásica y buena parte del medioevo, en que las funciones de autor y escriba estaban disociadas. El autor del texto no era el autor de las marcas; el autor de las marcas ejecutaba un trabajo manual. Para que el texto circulara intervenían los copistas. Si el texto necesitaba un tratamiento gráfico peculiar, intervenía un nuevo personaje: el iluminista.

A medida que la tecnología avanzó (tecnología en la preparación de las superficies y en los instrumentos para marcar - o sea, escribir - en esas superficies) el autor del texto y el autor de las marcas se fusionaron en una misma persona. Pero para la circulación de los textos intervenía una cantidad de profesionales. Con el andar de los siglos todos esos profesionales de la edición quedaron agrupados bajo el sello de una casa editorial. Ahora, por primera vez, se crean las condiciones para la desaparición de todos esos personajes. (No digo que vayan a desaparecer sino que se crea una posibilidad de desaparición que les concierne... sobre todo después del episodio Stephen King que en 2000 hizo temblar a los editores)

Ahora, por primera vez, un autor puede ser su propio editor en un doble sentido: primero, porque puede dar a su texto un formato gráfico a voluntad (incluyendo la incorporación de sonido e imágenes en movimiento); segundo, porque puede distribuir su texto a través de Internet. (Está más difícil que pueda obtener réditos económicos de esta distribución, pero ese es otro problema vinculado a los derechos autorales, de lo cual no voy a hablar).

De la organización monacal de los copistas a la organización mercantil de la edición a partir de la imprenta hay un salto cualitativo. Otro salto cualitativo se produce ahora, y nadie debe minimizarlo. El modo de producción y de distribución de los textos cambia radicalmente en cada uno de estos períodos.

También cambian las ideas de "unidad de la obra" e "identidad de autor", ideas a las cuales nos hemos habituado desde la época mo- 
derna. Ambas están íntimamente relacionadas a un soporte material que contribuye a hacer tangibles dichas nociones. Aunque la página de título incluyera un nombre de autor desde el siglo XVII, el estatus jurídico del autor será apenas reconocido a fines del siglo XVIII. Por enraizada que nos parezca tal idea de autor, ella tiene apenas dos siglos de estar plenamente constituida. La idea de autor "no es una idea medieval". ${ }^{1}$

Concomitante con la idea de autor es la idea de obra cerrada, concluida, publicada. ¿Volveremos a la inestabilidad propia al texto medieval? Cerquiglini, en su provocativa obra Eloge de la variante discute los efectos que opera la edición moderna de los textos medievales, particularmente en lo relativo a la segmentación de palabras, a la puntuación, y la búsqueda de UN original del cual los otros ejemplares serían copias con distinto grado de fidelidad o falsedad. Lo esencial de los textos medievales, según Cerquiglini, es la variación, precisamente por la ausencia de idea de autor. (Los siete manuscritos completos de la Chanson de Roland son otras tantas versiones o realizaciones de la epopeya, según Cerquilini, quien agrega: "Es difícil aceptar la idea que habría más de una Chanson de Roland, todas ellas auténticas", p.63).

En términos de las prácticas sociales de lo escrito, ¿qué es novedad y qué es retorno a épocas precedentes? En pantalla, los textos se despliegan en vertical. El desplegado en vertical del texto es, en cierto sentido, retorno al rollo (anterior al codex). No hay nada similar al gesto de hojear en las nuevas tecnologías, un gesto instituido por las hojas ensambladas en el codex. La inestabilidad del texto puede concebirse como un retorno a prácticas medievales, así como la fragilidad de la autoría. Antes de la im-

1- Cerquiglini, B. Ëloge de la variante. Histoire critique de la Philologie . Paris : Ëditions du Seuil, 1989.

Chartier, R. Libros, lecturas y lectores en la Edad Moderna (Cap. 3 : « ¿Qué es un autor? ?). Barcelona: Alianza Universidad, 1992.

Chartier, R. Entre poder y placer (Cap. V: "La invención del autor") Madrid: Ediciones Cátedra, 2000. prenta, no hay necesaria unidad temática en los códices. Por el contrario, lo más común es que el contenido del codex sea una antología, un conjunto de textos reunidos por razones diversas, sin necesaria unidad temática. La pérdida de unicidad temática no sería entonces un ataque al libro sino un retorno al codex anterior a la imprenta. Puestas en perspectiva histórica las TIC adquieren nueva dimensión. El ejercicio no es banal y tiene consecuencias, como veremos. ${ }^{2}$

Estamos en un dominio donde primero las cosas se dicen en inglés y luego se traducen, con poca o nula fortuna, a las otras lenguas. No hay una buena equivalencia entre el inglés "literacy" y el español "alfabetización". "Literacy" es más apto para designar el aprendizaje de las prácticas sociales vinculadas con la producción, uso y circulación de lo escrito, mientras que el español "alfabetización" remite más directamente al aprendizaje del alfabeto como tal.

Sin embargo, las palabras designan lo que los usuarios, siempre cambiantes, hacen con ellas. Una búsqueda por Internet nos informará rápidamente que el término "literacy" aparece a menuco asociado a expresiones vinculadas con las TIC:

\section{Information literacy \\ Computer literacy \\ Digital literacy \\ Media literacy \\ Web literacy}

(Términos bastante intercambiables, aunque se hayan intentado sistematizaciones diferenciadoras que aún no cuajan en el uso).

Pero también encontramos:

Scientific literacy

2- Ver Ferreiro, E. Pasado y presente de los verbos "leer" y "escribir" Buenos Aires y México: Fondo de Cultura Económica, 2001. 
Technology literacy

Environmental literacy

Cultural literacy

Health literacy

Visual literacy (como la capacidad de "leer el lenguaje corporal y gestual”)

Nos alejamos aún más de lo escrito con expresiones como:

\section{Economic literacy \\ Finantial literacy \\ Baseball literacy}

Por ejemplo, la expresión "baseball literacy" no se refiere a alguien que lee mucho sobre baseball sino alguien que tiene una cierta competencia (proficiency) en los saberes prácticos asociados a ese deporte.

¿Qué significados queremos transmitir cuando, a partir del inglés, hablamos de "alfabetización informática, digital o multi-media?” En el ambiente bibliotecológico ${ }^{3}$ hay menos dificultades para utilizar estas expresiones porque asumen que están ligadas a la búsqueda de información, y los modos de obtención de información han cambiado drásticamente. Ya no se busca información en los índices de los libros, en las enciclopedias o diccionarios y, mucho menos, en los ficheros que han sido o están siendo destruidos. Se busca información en bases de datos digitalizadas y hay que aprender a usar "palabras claves" y operadores lógicos elementales para orientar la búsqueda. En el ambiente bibliotecológico definir cuáles son las habilidades requeridas para la búsqueda informática es tema de debate, pero es mucho más simple que cuando hablamos aparentemente de "lo mismo" en el ámbito educativo.

En el ámbito educativo no se trata únicamente de buscar información sino de hacer algo con ella, transformando la información en conocimiento. Al bibliotecario no le importa

3- Ver sitios Web de la American Library Association y enlaces. qué va a hacer el usuario con la información obtenida. Tampoco le importa si la información que el usuario obtuvo, y que parece satisfacerlo, es la que realmente requería para el problema que trata de resolver.

Para el educador, en cambio, el proceso de búsqueda de información es apenas una etapa entre los dos momentos cruciales: elaborar una pregunta que haga pertinente la búsqueda y concluir construyendo nuevo conocimiento ${ }^{4}$.

En el contexto educativo, ¿qué podemos entender por "alfabetización informática, digital o multimedia"?

Para responder es útil hacer un breve recorrido por las relaciones entre tecnología y educación. Obviamente, hablo de la educación como institución social, formalmente organizada. Por supuesto, no ignoro que la escuela está lejos de ser el único ámbito educativo, pero estamos en una época en que ocurren fenómenos que han magnificado el "efecto escolar": por una parte, la edad de ingreso ha ido bajando progresivamente - en los países más desarrollados prácticamente todos los niños están escolarizados a los tres años, y los otros países aprueban legislaciones que van en el mismo sentido, sin hacer el mínimo análisis de las condiciones de viabilidad de tales legislaciones. Por otra parte, la llamada educación básica obligatoria se ha extendido hasta los 15 años, absorbiendo parte de lo que antes se llamaba "la escuela secundaria o de segundo grado”. Pero, además, la importancia que han adquirido los diplomas es tal que justifica la controvertida y reciente declaración de la OCDE según la cual la educación se ha convertido en "un servicio objeto de comercio".

4- La construcción de conocimiento no se reduce a "dar sentido" a fragmentos de información (en inglés: "to make sense" ). Tratar de dar sentido a la información es lo propio de la cognición humana. Pero, para decirlo en términos de la teoría de Piaget, la pura asimilación sin acomodación no es suficiente. Esto es muy evidente en el caso del conocimiento de la Historia donde los intentos por ligar entre sí informaciones dispersas, vagamente relacionadas, dan lugar a los más soberbios disparates. 
Por todas esas razones resulta pertinente poner el foco en las relaciones entre tecnología y educación, pensando específicamente en las instituciones escolares y en la educación básica. De la educación superior no voy a hablar por varias razones. Porque allí es muy evidente el uso intensivo de las nuevas tecnologías que se realiza, ya sea al nivel de los cursos en línea como en la renovación de las bibliotecas, las redes de investigadores trabajando conjuntamente a través de varios países, la transmisión de algunas técnicas especializadas a través de realidad virtual, y una larga lista de etcéteras.

En cambio, a nivel de la educación básica aparecen resistencias, dificultades, en todo caso baja utilización, incluso en los países más avanzados (En Francia, el Ministerio de Educación se inquieta porque apenas $20 \%$ de los maestros utilizan herramientas multi-media en clase, octubre 2003) ${ }^{5}$. Todo lo cual contrasta con la enorme propaganda hecha por las agencias internacionales sobre los inmediatos beneficios educativos que podrían derivarse del uso de las nuevas tecnologías y las igualmente enormes inversiones hechas por los gobiernos respectivos. (Todos los ministros de educación de América Latina son coincidentes: Internet en todas las escuelas es primera prioridad. Declaran metas de compras de equipo en ocasiones solemnes, por ejemplo al inicio del año escolar) ${ }^{6}$.

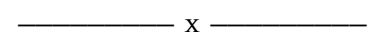

La institución escolar cuenta con tecnologías propias, heredadas por tradición, que conserva como si se tratara de símbolos patrios: el pizarrón o pizarra grande, donde se escribe

5- Dossier "L'édition scolaire numérique", suplemento de La lettre de l'éducation, $n^{\circ}$ 426, 6 octubre 2003, periódico Le Monde.

6- Al inicio del año escolar, septiembre 2003, el Secretario de Educación de México anuncia la intención oficial de adquirir 815,000 computadoras. También al inicio del año escolar, marzo 2004, el Ministro de Educación de Argentina anuncia un plan para adquirir 50,000 computadoras en los próximos 3 años. La diferencia en las cifras corresponde al tamaño de la población escolar de referencia, no a las intenciones. Ver sitios web oficiales de ambos países. con tiza o gis (pizarra que en francés se sigue llamando tableau noir aunque ya sea mayoritariamente de color verde oscuro; pizarra que en ambiente universitario ya es una superficie blanca en la cual se escribe con plumón, pero que sigue siendo invariablemente una superficie de madera pintada de negro o de verde oscuro en la inmensa mayoría de las escuelas de América Latina y, sospecho, de muchas otras partes del mundo). La institución escolar también conserva celosamente la tecnología del cuaderno escolar, heredera de las pequeñas pizarras individuales.

La institución escolar adoptó (junto con innovaciones en su modo de organización) una tecnología ajena: la pluma metálica, que sustituía con éxito a la pluma de ave, la cual debía tallarse constantemente. Sospecho que el éxito de la pluma metálica, que hizo bajar drásticamente la edad de utilización de la escritura con tinta, estaba vinculado a la semejanza con el instrumento anterior. Por algo ambas se llaman "plumas", aunque la segunda ya no guarda ni siquiera semejanza figural con la pluma de ave. El tintero subsistía. El gesto de ir con la pluma del tintero hacia la hoja, extremando precauciones para evitar una mancha que iría a estropear todo, subsistía. La innovación consistía, en el fondo, en la proscripción de un arma en el contexto escolar: el instrumento que aún hoy llamamos “cortaplumas". Y sobre la prohibición de armas en el contexto escolar hay consenso por anticipado.

Pero esa misma institución reaccionó con fuerte rechazo a la aparición del siguiente avance tecnológico: el bolígrafo, instrumento de escritura que cargaba consigo la tinta, que impedía por lo tanto el riesgoso gesto de ir del tintero al papel, que, de hecho, hacía inútil el hueco dejado en los pupitres para el famoso tintero y que, por añadidura sustituía la punta aguda de la pluma metálica (instrumento de agresión más de una vez) por una punta redondeada. Frente a todas estas ventajas la escuela-institución reaccionó con un NO rotundo y con razones que 
hoy día suenan a defensas ridículas: el nuevo instrumento (el bolígrafo) iba a "arruinar la letra” de los escolares. Claro, estábamos entonces en la transición entre la caligrafía como objetivo escolar y la cursiva legible (pero no necesariamente caligráfica) que terminó por imponerse.

La institución escolar libra a menudo batallas perdidas de antemano, pero las libra en aras de mantener "sus propias tecnologías", y esto hay que tenerlo en cuenta. También luchó contra las calculadoras de bolsillo, y por las mismas razones: iban a "arruinar el cálculo" de los escolares. Penosamente, y muy a pesar suyo, tuvo que irlas aceptando y mucho más penosamente aprendió a utilizarlas inteligentemente, cuando descubrió que la mecánica del cálculo podía ser delegada en ese instrumento, pero el cálculo aproximativo inteligente quedaba siempre a cargo del alumno, quien era el único capaz de estimar si el resultado era plausible o disparatado, por error en la pulsación de las teclas. La reintroducción del cálculo estimativo como actividad inteligente y la delegación del cálculo exacto como actividad mecánica es aún hoy día característica de algunas buenas escuelas en algunos lugares del planeta, y de ninguna manera un signo distintivo de la adopción de una nueva tecnología por parte de la institución escolar.

Otra de las tecnologías de la escritura a las que he hecho referencia - las llamadas "máquinas de escribir" (mecánicas o eléctricas) - fueron siempre rechazadas por la institución escolar. En múltiples encuestas hechas con maestras y maestros de América Latina he recibido siempre la misma respuesta: "hacen mucho ruido", razón suficiente para mantenerlas fuera del ámbito escolar. En realidad, las máquinas de escribir entraron en la burocracia escolar pero no en los salones escolares. Ni siquiera hubo "talleres de máquina de escribir", tal como ahora tenemos "talleres de cómputo", lo cual quiere decir salas separadas, nada que ver con el recinto sagrado llamado sala de clase. Las máquinas de escribir, aunque eran sin ninguna duda instrumentos de escritura muy poderosos, fueron mantenidas alejadas del ámbito docente (aunque hubieran entrado en el aparato burocrático escolar) por varias razones que, sospecho, están ligadas con lo siguiente: en primer lugar, una ruptura demasiado evidente con los modos de escritura anteriores (dos manos que escriben en lugar de una); en segundo lugar, como ya lo dije, la asociación de este modo de escritura a un saber técnico específico (el saber de las secretarias que aprendían en escuelas de dactilografía, o el saber de los escribas públicos que asisten a los usuarios en lugares predeterminados). La necesidad progresiva de "llenar a máquina" los formularios no fue razón suficiente para que la escuela se ocupara de esta tecnología, que nunca entró realmente en el ámbito de la docencia elemental o básica, a pesar de sus innegables ventajas.

Pasemos a una tecnología más reciente: la TV. Esta tecnología fue objeto de discursos encendidos en un doble sentido. Algunos celebraron sus ventajas educativas (y, de hecho, aparecieron y aún subsisten programas educativos compensatorios para zonas alejadas sostenidos por televisión, para jóvenes, no para niños, como la "Telesecundaria" mexicana). Otros, desde un discurso de izquierda, y frente a la invasión del espacio familiar por la TV comercial, reclamaban una "alfabetización" específica, destinada a la "lectura crítica" de los mensajes televisivos. El debate acabó en los hechos: la TV educativa tiene su ámbito propio en programas para zonas rurales o aisladas, principalmente para jóvenes o adultos, y algunas escuelas tienen TV, pero asociada a una videocasetera. 0 sea, poco o nada se utilizan las transmisiones en directo de TV, que constituyen una disrupción para el apretado calendario escolar. La biblioteca escolar se amplió, eventualmente, con un acervo de cintas video para apoyar la enseñanza de contenidos específicos: lenguas extranjeras o contactos con espacios geográficos distantes o especies animales de todo tipo (por ej, las series de National Geographic). 
En resumen, la relación entre el desarrollo de tecnologías de uso social y la institución educativa es un tema complejo. En general, las tecnologías vinculadas con el acto de escribir tuvieron repercusiones (no siempre positivas, como fue el caso del bolígrafo y la máquina de escribir). Pero la institución escolar es altamente conservadora, reacia a la incorporación de nuevas tecnologías que signifiquen una ruptura radical con prácticas anteriores. La tecnología de las PC e Internet dan acceso a un espacio incierto, incontrolable; pantalla y teclado sirven para ver, para leer, para escribir, para escuchar, para jugar..... Demasiados cambios simultáneos para una institución tan conservadora como la escuela.

Aquí se justifica una pregunta: ¿no serán precisamente las TIC que harán estallar la institución escolar? Efectivamente, algunos apuestan a ello. Suponen que, a corto plazo, cada niño, desde su casa podrá estar conectado a la mejor oferta educativa en línea, siguiendo a su propio ritmo los estudios, sin necesidad de desplazarse en nuestras mega-ciudades peligrosas. Por supuesto, uno recuerda a estos "visionarios" que la escuela es también una importante instancia de socialización en años cruciales de la formación de la personalidad. La objeción no los amedrenta. Reconozcamos que el espacio fundamental de socialización es el recreo. De acuerdo. Pues bien, clubes deportivos reemplazarán a las escuelas en lo relativo a la socialización y las actividades físicas, con mayor éxito, según esta visión al mismo tiempo tremendista y optimista, que constituye la apuesta máxima acerca del impacto de las TIC en la educación.

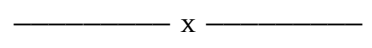

La situación es por demás conflictiva porque, como ya lo señalé, hay enormes expectativas sociales puestas en la educación para resolver todo tipo de cosas que obviamente ningún sistema educativo, por sí mismo, podrá resolver mientras continúen las desigualda- des sociales, mientras aumente la pobreza en los países del mal llamado "sur en desarrollo", mientras el desempleo o el malempleo sea una de las expectativas más realistas a pesar de la acumulación de diplomas, mientras la lista de los elegidos de Forbes nos informe que una sola familia (o una sola persona) tiene ingresos superiores al PIB de varios de los pequeños países del planeta, mientras los expertos internacionales vivan produciendo reportes y "evaluaciones externas" que poco o nulo impacto van a tener en los fenómenos que los ocupan: la reducción de la pobreza, la calidad de la educación, la equidad, transparencia, eficiencia y eficacia de los sistemas educativos.

Los países pobres, los "mal desarrollados", atados a los mecanismos reproductores de la deuda externa, continúan endeudándose para "poner computadoras en todas las escuelas", sin que haya el menor debate propiamente educativo sobre lo que eso significa. No es lo mismo "poner bancas y sanitarios en todas las escuelas" que poner computadoras en todas las escuelas. Las computadoras requieren soporte técnico permanente; requieren actualización permanente del software; requieren una línea telefónica o un cableado que garantice la conexión a Internet. Poner computadoras en todas las escuelas sin pensar en la infra-estructura indispensable requerida es poner algo inútil, que se convertirá en obsoleto pocos meses después de instalado. (El reciclaje cada 3 años, además, contribuirá de manera poderosa al endeudamiento auto-reproductivo porque no hay un extenso e intensivo debate sobre las ventajas del software libre).

Porque el sistema educativo, tanto como la burocracia estatal, posee múltiples "mecanismos de defensa" para luchar contra las intrusiones. Uno de esos mecanismos consiste en faire semblant: parece que acepta pero en realidad rechaza. Lo hemos podido comprobar en el detalle de los hechos con la instalación de las bibliotecas de aula en México. Pero no es sólo México (país líder en América Latina en la 
producción de obras de gran calidad de distribución gratuita en las escuelas). La idea misma de bibliotecas escolares es muy antigua, y hay testimonios múltiples y coincidentes de esas bibliotecas como espacios cerrados y acotados -- "la bibliotecaria no vino"--, espacios de custodia pero no de préstamo, como si la tradición monástica medieval se perpetuara en pleno siglo XXI en el espacio escolar. Lo mismo ocurre con los equipos de cómputo: se ubican en una sala aparte, cerrada con llave "para proteger el equipo", a cargo de un "maestro de cómputo que hoy no vino", con una utilización acotada que a veces se maneja como premio para los alumnos sobresalientes.

Pocos son los maestros disponibles para dejar entrar los libros (en plural, o sea, una biblioteca de aula); menos son los maestros disponibles para dejar entrar la computadora en el salón de clase (elemento de distracción, tanto como los libros). Es ya un lugar común decir que el maestro se siente desplazado por una tecnología atractiva que suscita - ya lo sabemos - actitudes lúdicas y no necesariamente actitudes de aprendizaje. Y cuando parece que los/las docentes las utilizan, vemos que hacen un uso accidental y acotado: buscar una información en un sitio predeterminado.

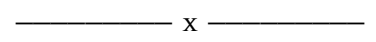

Varios “escenarios posibles”, a corto plazo.

Escenario 1 (ideado por Microsoft) - Todos los niños irán con su notebook a la escuela (muchos de ellos donados por la fundación de Bill Gates). Cargarán en ese equipo toda la bibliografía de todos los cursos, con lo cual terminaremos con las nauseabundas fotocopias, una tecnología que arruinó el gusto por los libros, que dio el mismo aspecto físico a todas las páginas y que fragmentó los textos, mucho antes de que Internet lo hiciera. Que también atentó contra los derechos de autor, mucho antes de que Internet lo hiciera. Incluso atentó contra la identidad de los autores, que desaparecían en las fotocopias de fotocopias que circulaban en los países mal desarrollados. Los maestros serán tutores, advisors, consejeros... Harán muchas cosas, excepto dar clases. Los verdaderos “maestros" estarán ausentes o, mejor dicho, virtualmente presentes. Algunos compañeros también tendrán una presencia virtual. Y, como ya sabemos, el chat sirve para todo, inclusive para iniciar relaciones amorosas, no menos exitosas que las que se inician en contacto presencial. El "cara a cara" y "cuerpo a cuerpo" que ha jugado un rol nada despreciable en los contactos educativos de épocas precedentes tiende a desaparecer. Así evitaremos también los contactos corporales potencialmente peligrosos entre los miembros de la comunidad educativa. Los únicos cursos presenciales se reducirán a cursos introductorios de "nivelación" para asegurar que todos los alumnos tengan similares habilidades informáticas. (Aunque es dable imaginar que el preescolar y quizás los primeros años de la primaria sean de tipo presencial, al menos hasta que se descubra cómo enseñar a leer y escribir sin la presencia de un humano...)

Escenario 2 (conservador) - Algunos niños tendrán sus espacios TIC fuera de la escuela. La escuela asumirá esos saberes "extra-escolares" (como asume que los alumnos saben usar una TV, grabar un programa, etc). Después de todo, la escuela nunca enseñó explícitamente a utilizar los celulares y cualquier chico lo aprendió en la casa o con sus compañeros. Tampoco se dedicó a enseñar cómo se maneja un control remoto de TV. En todo caso, la escuela se limita a decir "vean hoy a las 6 de la tarde en el canal 11 un programa sobre los osos polares; mañana vamos a comentarlo en clase”. La escuela no enseña "el lenguaje de las imágenes”. De la misma manera, podrá pedir que busquen información sobre tal o cual cosa en Internet, incluso podrá recomendar algunos sitios, asumiendo implícitamente que la rápida diseminación de esta tecnología le exime de enseñar un "saber hacer" puramente tecnológi- 
co. ¿La brecha digital? Bien gracias. La escuela no la creó; es uno de los tantos males sociales que afectan su propio funcionamiento pero está fuera de sus capacidades el modificar esos males sociales. ¿Cómo pretender que la mayoría de los docentes, mal pagados y peor capacitados, enseñen a circular en los más de 50 millones de sitios web identificados en abril 2004?

Escenario 3 (peligrosamente idealista) - Las TIC constituyen una revolución de tal magnitud que cambia radicalmente los procesos de lectura y escritura y, en particular, marca la desaparición de la "linealidad alfabética". El conocimiento no se trasmitirá más a través del lenguaje escrito sino a través de complejas relaciones entre imágenes (de preferencia en movimiento), gráficos, cápsulas informativas (en audio o escritas). Lo esencial es aprender a interpretar mensajes transmitidos por todos estos medios simultáneamente, pero también producir mensajes utilizando las tecnologías de punta. La escuela asume como su función primordial esta nueva "alfabetización digital multi-media” y relega los tradicionales contenidos curriculares a segundo plano, ya que la velocidad de los cambios en los saberes que hay que incorporar "para la vida" hace rápidamente obsoleto cualquier currículo. Además, la velocidad de los cambios en las mismas tecnologías obliga a dedicar un tiempo considerable al reciclaje permanente de los propios usuarios (incluso expertos). Los maestros serán reemplazados por técnicos informáticos, con formación actualizada en comunicación ya que, en palabras de algunos de sus promotores, "la alfabetización multimedia (...) se ocupa de enseñar a leer y escribir con texto, sonido e imágenes en documentos no lineales e interactivos" ${ }^{7}$. Cuando leemos los Information Literacy Standards ${ }^{8}$ que se están promoviendo en USA - desde Pre-K

7- La cita es de la p.65 del libro de A.Gutiérrez Martín, Alfabetización digital (Barcelona: Gedisa, 2003). Por supuesto, hay una sobreabundancia de textos dedicados a este tema, y no es mi intención hacer una revisión bibliográfica crítica.

8- <http://cnets.iste.org/currstands/cstands-il.html> hasta Grade 12 - es evidente que "ellos" no están pensando en escuelas, como las de América Latina, donde los alumnos van apenas 4 horas por día a clase: todo el tiempo escolar estaría dedicado a adquirir esas técnicas de comunicación, sin más tiempo disponible para los contenidos sustantivos del currículo (y suponiendo que hubiera 20 alumnos por clase, en lugar de los 35 o 40 que hay ahora; suponiendo que hubiera muchas máquinas disponibles, tiempo gratuito de acceso a Internet, soporte técnico, actualización de máquinas y programas y todo lo demás)

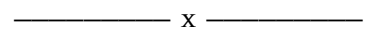

Este escenario 3 viene presentado a veces con un discurso progresista y bienpensante; a veces, simplemente con el futurismo implacable de los visionarios. Pero cualquiera sea el tipo de discurso con el cual viene presentado, lo cierto es que empalma muy bien con la ideología de la "sociedad del conocimiento" que promocionan el World Bank y agencias asociadas. Y aquí es necesario detenerse un poco a reflexionar.

La nueva economía es caracterizada como una knowledge economics. De hecho, James Wolfensohn, presidente del World Bank (WB), propuso en 1996, y reiteró en 1999, que el WB se redefiniera como un Knowledge Bank. La expresión knowledge management aparece regularmente en documentos recientes de esa agencia y de otras, como OCDE. ¿De qué “conocimiento" se trata? De un conocimiento práctico, inmediatamente aplicable, rápidamente perimible (están convencidos que estos conocimientos tendrán una vida útil de unos 3 años, en promedio), una mercancía como cualquier otra, con un valor en el mercado. Por supuesto, todos dicen que el conocimiento no debe confundirse con la información, pero en el discurso todos los términos se confunden y, curiosamente, learning queda con frecuencia totalmente disociado de knowledge. 
Las instituciones que tradicionalmente se asociaban con el knowledge (es decir, las universidades) quedan francamente desplazadas, a menos de ajustarse a este modelo, lo cual por supuesto está ocurriendo. En principio, este nuevo knowledge estará disponible en otros lugares y está ya disponible, al menos en parte, en las autopistas informáticas.

¿Dónde se van a adquirir los conocimientos que se requieren para esta nueva dinámica económica? La expresión clave es learning communities. Esta expresión es extremadamente ambigua y, quizás, deliberadamente ambigua. Una comunidad de aprendizaje puede tener existencia local (una empresa, una familia, una comunidad rural, o lo que sea) o puede tener existencia virtual (grupos conectados por Internet). También una escuela podría caracterizarse como una comunidad de aprendizaje. Pero la escuela deja de ser el lugar por excelencia de los aprendizajes, y eso es lo que importa.

No nos engañemos: no se trata del conocimiento científico, el que busca la inteligibilidad, que crea sistemas comprensivos (que llamamos teorías), que exige demostraciones, contraste y discusión, que aporta pruebas de la validez de sus afirmaciones y formula constantemente preguntas en función de "huecos a la inteligibilidad". Ese conocimiento queda fuera de este nuevo knowledge. No se trata de discutir si el conocimiento científico es complementario, opuesto o lo que sea con respecto a otros conocimientos (el conocimiento popular, el conocimiento tecnológico, etc). Lo grave es el monopolio de las palabras. Los nuevos economistas se han apropiado la palabra knowledge. Este knowledge es concebido como encapsulado y encapsulable; desechable, perimible. Por eso, aprender a desechar les parece a ciertos ideólogos tan importante como aprender a "cargar información"; los individuos humanos no vienen equipados con una tecla delete y por eso hablan de la necesidad de entrenar forgetting habilities (habilidades para olvidar).

Como estamos en una economía de mercado, la velocidad cuenta y tiene precio. En pala- bras de un alto directivo del World Bank: "La educación tradicional es una educación just in case; necesitamos reemplazarla por una educación just on time". (Es preciso conservar esas expresiones en inglés para apreciar adecuadamente el impacto que la valoración de la velocidad y la aplicabilidad inmediata tienen en el discurso dominante). En otro contexto, un alto ejecutivo de Microsoft, al hacer el elogio del e-book y anunciar, de paso, la muerte de la escritura en papel, pronuncia estas palabras clave, que encierran un claro contenido ideológico: "Ya no hay distinción entre ricos y pobres, grandes y chicos. La única distinción es entre rápidos y lentos". ${ }^{10}$

En toda esta discusión hay un gran ausente, que es la noción misma de aprendizaje que se está utilizando. ¿A qué velocidad máxima pueden producirse aprendizajes? ¿Qué es lo que se puede aprender a través de las pantallas? El aprendizaje es un proceso, y es un proceso que lleva tiempo. Es muy probable que las tradicionales edades para iniciar tal o cual tipo de aprendizaje deban ser revisadas. Pero seguramente hay aprendizajes que exigen el "cara a cara y cuerpo a cuerpo", tanto como hay aprendizajes fundamentales que exigen el contacto efectivo con los objetos. Una gran tarea de la psicología y la psicopedagogía del futuro inmediato será descubrir cuáles son los aprendizajes que NO se pueden hacer a través de las pantallas.

Las TIC han llegado envueltas de un discurso ideologizante del cual debemos intentar despojarlas para valorarlas por sí mismas.

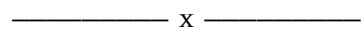

La interconectividad es sinónimo de economía global. Y por eso en julio 2000, en Okinawa, Japón, durante la reunión del G-8, se tomó la decisión de establecer una Dot Force (= Digital Opportunity Taskforce) para superar el Digital Divide, luego de tomar nota

9- Registrado por la autora, participante de un Global Dialogue organizado conjuntamente por UNESCO y el World Bank en Alemania, 2000.

10- Registrado por la autora, participante del Congreso Mundial de Editores realizado en Buenos Aires, 2000. 
de informaciones de este tipo: en ese momento había (y probablemente sigue habiendo) más conexiones a Internet en Manhatam que en toda Africa. (Apréciese el lenguaje militar de la denominación: Taskforce) El Digital Divide preocupa hoy más que todas las otras desigualdades ya conocidas, y por ello se destinarán (al menos eso se dijo) 60.000 millones de dólares por año para infraestructura en comunicaciones (lo que no incluye computers).

La brecha digital existe, sí, y se superpone a la brecha de la alfabetización que ya conocíamos, esa deuda eterna que venimos arrastrando. Estamos en la década de la alfabetización, según la UNESCO, cuyo actual director general ha tenido la peregrina idea de nombrar a Mrs. Bush "embajadora especial" de dicha década, sin duda para celebrar el reingreso de USA a la UNESCO después de unos 20 años de ausencia.

Pero en la famosa reunión de Jomtien, Tailandia, de 1990, cuando el World Bank firmó junto con la UNESCO la declaración de prioridad absoluta a la educación básica, ya se habían establecido las metas para los últimos diez años del siglo XX: educación para todos $\mathrm{y}$, por supuesto, alfabetización para todos.

Y mucho antes, en 1979, los ministros de educación y los encargados de la planificación económica de América Latina y el Caribe fueron convocados por la misma UNESCO en la ciudad de México, donde se comprometieron a lograr, antes del 2000, la escolarización de todos los niños, una educación general básica de ocho a diez años y la eliminación del analfabetismo. Fue el inicio de lo que se conoció con el nombre de Proyecto Principal de Educación para América Latina y el Caribe. Por supuesto, reuniones similares se realizaron en otras regiones.

Y así vamos, de declaración en declaración, de celebración en celebración, mientras un grupo cada vez más numeroso de "expertos" viven holgadamente de la pobreza que denun- cian (por eso de las evaluaciones "externas" que garantizan la homogeneización de las políticas mucho más que la tan mentada "transparencia”).

Así vamos, de un compromiso previo incumplido hacia el siguiente, sin hacernos cargo de nuestra propia historia de fracasos, mientras que Europa y el norte del continente Americano son invadidos por inmigrantes no deseados, mientras los huérfanos del SIDA y de las nuevas "guerras preventivas" claman justicia con ojos desorbitados, mientras aumenta el número de los que sobreviven (y mal viven) con menos de un dólar diario, mientras el incremento de la concentración de la riqueza en pocas familias y pocas empresas es tan escandaloso como el número de niños que nacen con una esperanza de vida menor a los cinco años. ${ }^{11}$

¿Cómo alfabetizar en este mundo desigual? ¿Seguiremos haciendo propuestas para el 20\% de la población de este planeta? ¿Es la alfabetización digital la respuesta?

\section{$\longrightarrow \mathrm{x}$}

Como investigadora, hace 25 años que vengo luchando por ensanchar el concepto de "alfabetización" con una mirada que es a la vez evolutiva, social e histórica. Puedo decir y sostener con evidencias empíricas que alfabetizar no es franquear la "barrera del código". No lo es, primero, porque ningún análisis lingüístico serio permite concluir que las escrituras históricamente desarrolladas son códigos (en el sentido que sí lo son algunos lenguajes artificiales como el código Morse o el código binario). Segundo, porque lo esencial del proceso de alfabetización consiste en una reconversión conceptual: el lenguaje, aprendido como instrumento de comunicación, debe convertirse en un objeto independiente del acto de elocución, un objeto

11- Informe anual de UNICEF, presentado en Berlín el 7 de mayo de 2004: "La miseria crónica mata a un millón y medio de niños antes de cumplir los cinco años en los 10 países más necesitados del mundo". En Afganistán, por ejemplo, el 25\% de los niños no llega a cumplir los 5 años. 
sobre el que se puede pensar, un objeto a ser analizado. Tercero, porque la escritura históricamente constituida no es un reflejo de la oralidad sino un sistema de representación a varios niveles, que deja de lado - o sea, no representa - distinciones esenciales para la comunicación oral (énfasis, modulaciones entonativas, reiteraciones, pausas intencionales, esbozos y enmiendas) tanto como introduce distinciones ajenas a la oralidad (por ej., palabras que "suenan" igual se escriben diferente si hay cambio de significación referencial o sintáctica). Cuarto, porque entre "la lengua que se escribe" y la oralidad hay sensibles diferencias en todos los planos (pragmático, lexical, sintáctico e incluso fonológico). Y me detengo, aunque podría seguir con la lista. ${ }^{12}$

Las dificultades en el pasaje de lo oral a lo escrito subsisten, con o sin TICs. Lo que las TICs hacen, sin saberlo, es contribuir a:

- Hacer obsoleta la idea de alfabetizar con un único texto (pero hace décadas que somos muchos los que venimos insistiendo en la ventaja de la diversidad de textos desde el inicio).

- Hacer obsoleta la obsesión pedagógica por la ortografía (hay que aprender a utilizar inteligentemente los correctores ortográficos, al igual que las calculadoras de bolsillo).

- Hacer obsoleta la idea de una única fuente de información: el maestro o el libro de texto (pero hace décadas que las buenas bibliotecas y los buenos bibliotecarios vienen trabajando en esta dirección).

En síntesis, hay múltiples puntos de convergencia entre lo que se proclama como “novedades introducidas por las TICs" (en términos propiamente educativos) y lo que las tendencias progresistas en alfabetización (por

12- Ver Ferreiro, E. (Comp.) Relaciones de (in)dependencia entre oralidad y escritura. Barcelona: Gedisa, 2002. llamarlas de algún modo) vienen reclamando desde hace décadas. En ese sentido, ibienvenidas las TICs!

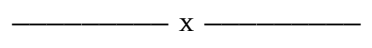

Regresemos al tema de las "novedades absolutas"-

¿Hay una novedad absoluta en la relación entre imágenes y texto? Sí, porque es posible introducir una imagen en un texto con una facilidad antes desconocida. Sí, porque es posible tratar un texto como una imagen y digitalizar ambos. Sin embargo, no exageremos. Desde el medioevo, y con fuerza decisiva desde la Ilustración, las imágenes acompañan a los textos y a veces sustituyen a los textos. (Después de todo, durante la conquista de América la doctrina católica se transmitió a menudo a través de imágenes, como lo prueba el Catecismo en pictogramas de Fray Pedro de Gante, inspirado en los códices del México pre-hispánico ${ }^{13}$ ).

¿Asistimos a una superación, desaparición o ruptura de la linealidad? Una vez más, ¿de qué estamos hablando? La búsqueda de información en un libro, un diccionario, una enciclopedia, un anuario telefónico o lo que sea, nunca fue lineal. Siempre fue un proceso con idas y vueltas, recogiendo trozos de información "a saltos", y con esa información fragmentada ir tomando decisiones. Pero en el momento en que se decide que se ha encontrado la información requerida, y si esa información se presenta bajo la forma de un texto escrito continuo, por breve que sea, la lectura es lineal. Internet hace circular textos sin transformarlos en no-textos.

$¿$ Hay recursos disponibles que permiten incorporar en la escritura elementos ausentes de la escritura alfabética? De acuerdo. Pero tampoco eso es totalmente nuevo. La propaganda comercial ha explorado con anterioridad muchos de esos recursos.

13- Cortes Castellanos, J. El catecismo en pictogramas de Fray Pedro de Gante Madrid: Fundación Universitaria Española, 1987. 
La mayor novedad, me atrevo a pronosticar, es la posibilidad de fragmentación, con todo lo que ello significa. El video experimentó con gran éxito la fragmentación y superposición de imágenes. El control remoto dio a los usuarios, y muy particularmente a los jóvenes, la posibilidad de cambiar rápida y continuamente de canal o de track, con una exploración mínima de la imagen visual o del estímulo sonoro. Los recursos informáticos permiten fragmentar y superponer a voluntad, imágenes y textos. Quizás estamos asistiendo, sin saberlo, a una nueva estética textual, donde los tradicionales análisis en términos de coherencia y cohesión ya no tienen mayor sentido. No lo puedo afirmar. Pero estoy convencida de que algunas tecnologías periféricas - como el control remoto - han tenido en las nuevas generaciones mayores efectos que los anticipados inicialmente.

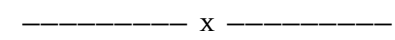

Para dejar clara mi posición, permítanme resumirla en estos términos. Yo no puedo hablar de alfabetización en el vacío sino en un espacio-tiempo determinado. $\mathrm{Cu}$ ando apenas despuntaban los ordenadores, $\mathrm{y}$ convencida del poder del teclado en las tecnologías en desarrollo, inicié una campaña de recuperación de viejas máquinas mecánicas de escribir para instalarlas en escuelas rurales de México. No tuvimos demasiado éxito en la campaña pero en las escuelas donde las pudimos llevar fue un gran suceso social entre adultos y jóvenes. Las imágenes de los niños de 5 y 6 años tratando de comprender el funcionamiento de ese objeto mágico me conmueven todavía.
Ahora también lucho por el acceso a los libros y a las TIC en todas esas escuelas y en todas las escuelas. ${ }^{14}$

Pero no hablo, porque creo que no corresponde hablar, de educación digital o de alfabetización digital. Hablo de alfabetización, a secas. La que corresponde a nuestro espacio y tiempo.

Necesitamos lectores críticos, que duden de la veracidad de lo visivo impreso en papel o desplegado en pantalla, texto o imagen; lectores que busquen comprender otras lenguas (icuánto más fácil ahora con Internet!) sin menospreciar ni magnificar el inglés hegemónico; que tengan una visión global de los problemas sociales y políticos (icuánto más fácil ahora con Internet!) sin encerrarse en localismos estrechos. Lectores y productores de la lengua escrita inteligentes, alertas, críticos. Lo que siempre hemos buscado. Difícil tarea, antes y ahora. Internet ayuda, qué duda cabe. Los libros y las bibliotecas también. Frente al conservadurismo de la institución escolar, las bibliotecas y los bibliotecarios pueden asumir un rol de vanguardia, bien diferente del rol compensador que algunos le atribuyen.

Necesitamos niños y jóvenes que sepan decir su palabra por escrito de manera convincente (icuánto más fácil ahora con Internet!); que no se comuniquen simplemente porque "hay que estar en comunicación permanente", sino que tengan algo para comunicar; que el contenido del mensaje cuente al menos tanto como la forma. Porque las nuevas generaciones deberán ser particularmente creativas. Tendrán a su cargo nada más y nada menos que la invención de un nuevo orden mundial donde la vida valga la pena de ser vivida.

14- Luchar por el acceso a las TICs significa también abrir el debate: ¿cuántas computadoras en cada escuela? ¿en qué tipo de redes? ¿equipadas con qué tipo de software? Y así siguiendo.

Emilia Ferreiro é psicolinguista, doutora em psicologia pela Universidade de Genebra e investigadora do DIE/CINVESTAV - Departamento de Investigaciones educativas do Centro de Investigação e Estudos Avançados do Instituto Politécnico Nacional, da Cidade do México. É autora de importantes pesquisas e livros no campo da psicogênese da língua escrita. E-mail: ferreiro@cinvestav.mx 